\title{
Controlling strength and toughness of multilayer films: A new multiscalar approach
}

\author{
D. P. Adams, M. Vill, J. Tao, J. C. Bilello, and S. M. Yalisove \\ Department of Materials Science and Engineering, University of Michigan, Ann Arbor, Michigan 48109
}

(Received 16 February 1993; accepted for publication 12 March 1993)

\begin{abstract}
Multiscalar films are produced in order to combine both toughness and strength into a multilayer film. These structures incorporate both a strengthening phase and a toughening phase in a compositionally modulated microcomposite. The mechanical properties and microstructure for thick $(\sim 50 \mu \mathrm{m}) \mathrm{Mo} / \mathrm{W}$ multiscalar films have been characterized. A detailed microstructural analysis (including transmission electron microscopy, scanning electron microscopy, and $\mathrm{x}$-ray techniques) of $\mathrm{Mo} / \mathrm{W}$ multiscalar films has shown that large single-crystal columns of Mo interspersed with epitaxial layers of $\mathrm{W}$ extend for the entire film thickness. The microstructure is a zone-II-type microstructure, yet the temperatures during deposition are well below the lower limit $\left(0.3 T / T_{m}\right)$ previously reported for such microstructures. Hardness and tensile tests have shown that a multiscalar approach is capable of tailoring a desired strength and toughness into a multilayered film.
\end{abstract}

\section{INTRODUCTION}

Compositionally modulated multilayers have received a great deal of attention for their unique mechanical properties. ${ }^{1}$ These microlaminate films typically consist of alternating thin layers of two different, yet complementary, materials. Multilayer structures have been fabricated using a number of growth techniques including sputtering, molecular-beam epitaxy, ${ }^{2}$ ion-beam deposition, ${ }^{3}$ and electrodeposition. ${ }^{4,5}$ The relationship between thin-film microstructure and mechanical properties is usually examined in order to optimize strength. Increases in strength are commonly observed in multilayer films and can arise from a number of mechanisms ${ }^{6-8}$ including Orowan strengthening and Hall-Petch strengthening. In many cases, the quality of the microstructure and the chemical modulation on a nanoscale is directly responsible for the activation of certain mechanisms and the degree to which the mechanical properties are enhanced. Therefore, considerable emphasis has been placed on growing high-quality, single-crystal microlaminates. Most work aimed at producing such multilayers for mechanical applications has included growth of metal or metal alloy superlattices. ${ }^{9-13}$ Multilayer films composed of metals with the same lattice structure and small lattice misfit have successfully been grown, as have high-quality metal bicrystal superlattices. ${ }^{14}$ In addition, ceramic-ceramic $^{15}$ and ceramic-metal ${ }^{16}$ multilayers have been grown which display exceptional hardness that depends critically on interlayer spacing and growth parameters. Compositional wavelengths are kept small (typically on the order of several monolayers: $2000 \AA$ ) for most work because of the inverse power-law $\left(d^{-1 / 2}\right.$ and/or $\left.d^{-1}\right)$ dependence of yield strength on layer spacing. For example, the strengthening mechanism proposed by Koehler ${ }^{6}$ for a multilayer structure consisting of layers with alternated high/low elastic moduli may render a Frank-Read source inoperative if layer thicknesses are kept small. However, regardless of which particular strengthening mechanism or combination of mechanisms is active, the toughness of thin, strong, multilayers remains minimal.

The present work combines the strength of thin, modulated multilayers with the toughness of a singlecomponent, ductile material into one film. These films differ from most multilayers by incorporating several scales of composition modulation into much thicker $(\sim 50 \mu \mathrm{m})$ coatings. As shown in Fig. 1, multiscalar films in this report consist of two phases-a toughening phase and a strengthening phase. Here, a thin W/Mo multilayer is used as the strengthening phase, while a thick layer of Mo is used as a toughening phase. Using this arrangement of distinct scales (thickness, volume fractions), the two phases can be chosen to tailor the overall toughness and strength of the microlaminate for specific applications.

\section{APPROACH}

In principal, multiscalar films could consist of any combination of strong and tough components including ceramics, metals, etc. In this study Mo and W layers were used as a model system to examine the effectiveness of a multiscalar design. These two refractories are favorable because each have the body-centered cubic lattice structure and low lattice misfit over a large range of temperatures $\left[\left(a_{\mathrm{W}}-a_{\mathrm{Mo}} / a_{\mathrm{W}}\right)\right.$ at $300 \mathrm{~K}=0.0058,\left(a_{\mathrm{W}}-a_{\mathrm{Mo}} / a_{\mathrm{W}}\right)$ at 1500 $\mathrm{K}=0.0052]$. Mo and $\mathrm{W}$ also have very high melting temperatures and an excellent match of thermal-expansion coefficients (Mo: $4.5 \times 10^{-6} /{ }^{\circ} \mathrm{C}$, W: $5.0 \times 10^{-6} /{ }^{\circ} \mathrm{C}$ ). Mismatch of thermal-expansion coefficients often limits the temperature range of multilayer composites for applications and makes growth of such multilayers at elevated temperatures difficult. Molybdenum was chosen as the toughening component of this refractory metal multiscalar film because of its lower elastic modulus. The strengthening phase consisted of a 29 layer stack of $40 \AA$ layers of Mo 


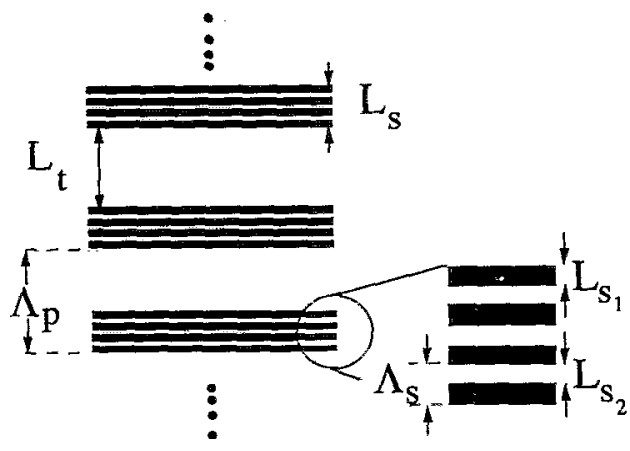

FIG. 1. Multiscalar films. $L_{s}$ is the thickness of the strengthening phase, $L_{t}$ the thickness of the toughening phase, $L_{s 1}$ the thickness of the first component of the strengthening phase, $L_{s 2}$ the thickness of the second component of the strengthening phase, $\Lambda_{t}$ the wavelength of the toughening layer, and $\Lambda_{s}$ the wavelength of the strengthening layer.

and $\mathrm{W}$. This scale (i.e., thickness) is kept small because of the inverse relationship between yield stress and interlayer spacing cited above.

Past studies have included investigation of the complex relation of residual stress and film thickness for both Mo and W. Double-crystal-diffraction topography has shown that large amounts of stress are locked into both Mo and W layers sputtered onto $\mathrm{Si}\langle 100\rangle$ wafers. ${ }^{17}$ Thin Mo films sputtered onto $\mathrm{Si}\langle 100\rangle$ wafers (with native oxide) were measured to contain residual compressive stresses as high as $1 \mathrm{GPa}$ for thicknesses of $25 \AA$, yet retained their structural integrity. W films sputtered onto $\mathrm{Si}\langle 100\rangle$ wafers also exhibited a high stress (on the order of $100 \mathrm{MPa}$ ) at film thicknesses of $10 \mathrm{~nm}$.

\section{EXPERIMENTAL PROCEDURE}

Mo/W multiscalar films were grown by sputtering Mo and $\mathrm{W}$ onto 3.0-in.-diam $\mathrm{Si}\langle 100\rangle$ wafers (as received, with native oxide). Si wafers were clamped to a flat stainlesssteel platter fixed 10 in. above both if (tungsten) and dc (molybdenum) sputtering sources in an Enerjet deposition system. Samples were rotated about the center of the platter at $20 \mathrm{rpm}$ in order to maintain uniformity in film thickness across the wafer. Each source was calibrated using a DEKTAK surface profile monitor and checked with Rutherford backscattering spectrometry (RBS) prior to growth. The deposition time was controlled manually by electrically switched Ta shutters to within an accuracy of $\pm 0.5 \mathrm{~s}$. The sputtering system was cryopumped (base pressures: $7 \times 10^{-6}$ Torr) with argon sputtering pressures maintained at $10 \mathrm{mT}$ Torr during growth. Si substrates were not biascd or heated during deposition. Two different sets of Mo/W multiscalar films were grown. One set was produced with a total thickness of $51 \mu \mathrm{m}$ and the other set was grown to a thickness of $31 \mu \mathrm{m}$. The $51 \mu \mathrm{m}$ set contained $1-\mu \mathrm{m}$-thick toughening phases and the $31-\mu \mathrm{m}$-thick set contained 5- $\mu \mathrm{m}$-thick toughening components. The strengthening phase was the same in both sets and contained 29 thin $\left(L_{s 1} \sim 40 \AA, L_{s 2} \sim 40 \AA\right)$ alternating Mo/W layers as detailed in Fig. 1. Strengthening phases were used as the initial and final layers for both sets of films. The thicker, toughening layer of Mo was deposited at a rate of $710 \AA / \mathrm{min}$ and each of the thin $\mathrm{W}$ and Mo layers were grown at 65 and $200 \AA / \mathrm{min}$, respectively. Slight increases in substrate temperature $\left(T<300^{\circ} \mathrm{C}\right)$ occurred during the run because of source heating. Uninterrupted deposition times totalled $26 \mathrm{~h}$ for the $51 \mu \mathrm{m}$ films and $15 \mathrm{~h}$ for the $31-\mu$ m-thick films.

The microstructure of the deposited films was characterized using scanning electron microscopy (SEM), transmission electron microscopy (TEM, both conventional and high resolution), $\mathrm{x}$-ray pole figure analysis, and whitebeam transmission diffraction. An Electro-scan SEM was used to characterize fracture surfaces of samples before and after pulling in tension. Cross-sectional TEM samples of these films were prepared by mechanical thinning to $\sim 50 \mu \mathrm{m}$ followed by ion milling to perforation. Milling consisted of bombardment with $5 \mathrm{kV}$ Ar ions with the sample maintained near $77 \mathrm{~K}$. Preparation of TEM crosssection samples using this technique did include a brief heating step $\left(T<100^{\circ} \mathrm{C}\right)$ to remove mounting wax. Samples were analyzed using both Philips 420T (operating at $120 \mathrm{kV})$ and JEOL 4000EX (400 kV) electron microscopes. Texture information was obtained using standard $\mathrm{x}$-ray pole figure techniques with a $\mathrm{Cu} K \alpha$ laboratory source and a Rigaku rotating anode $x$-ray generator. Transmission white-beam $(0.418-3.875 \AA)$ topographical analysis was conducted at the Stanford Synchrotron Research Laboratory using beam line 2-2.

Vickers hardness measurements were obtained using a Buehler microhardness indenter with camera and display unit. Si wafers with Mo/W multiscalar films were attached to stainless-steel positioning mounts using crystal bond. Loads of $10,25,50,100,200,500$, and $1000 \mathrm{~g}$ were used and care was taken to space indentations by at least 30 times the diagonal length. Depths of penetration into the foil were estimated by calculations based on indenter tip geometry and measured diagonal lengths. Hardness results are reported only for depths of penetration less than $25 \%$ of the film thickness.

Tensile testing consisted of pulling the multilayer films within the plane of the sheet. Films were either hand scribed or cut to size with an $\mathrm{Y}_{3} \mathrm{Al}_{5} \mathrm{O}_{12}$ (YAG) laser to widths of $6 \mathrm{~mm}$ with gauge lengths of $15 \mathrm{~mm}$, and then mounted between two $3 \times 1 / 2$ in. $^{2}$ pieces of brass on each end. The samples were fixed to the brass with a cyanoacrylate epoxy and then pulled in a model 4204 Instron tensile tester at rates of $0.05 \mathrm{~mm} / \mathrm{min}$. A full description of the tensile tests and fractography are published elsewhere. ${ }^{18}$

\section{RESULTS}

\section{A. Microstructure}

Detailed microstructural analysis of the multiscalar films has included an examination of the texture, layer structure, and interfacial order using $\mathrm{x}$-ray diffraction and electron microscopy. A SEM image, shown in Fig. 2, of a typical Mo/W multiscalar film fracture surface viewed in cross section, shows the ordered stack of strengthening 


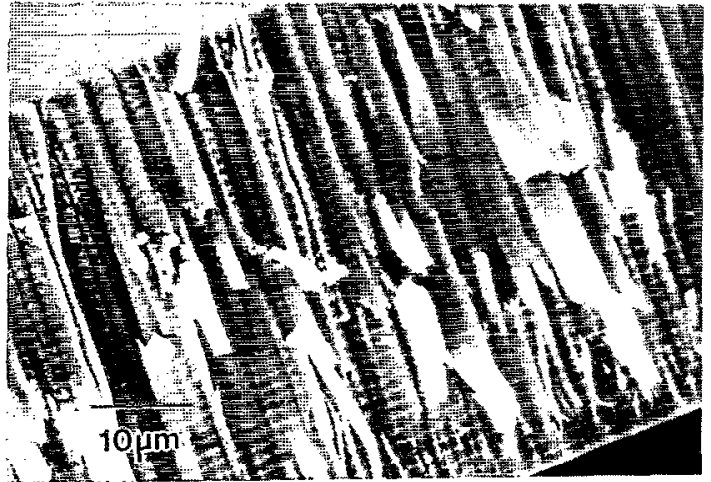

FIG. 2. Cross-sectional SEM micrograph of a typical $51-\mu \mathrm{m}$-thick Mo/W multiscalar film consisting of a $1-\mu \mathrm{m}$-thick toughening layer of Mo.

phases (lighter contrast) and toughening phases (darker contrast). Mo/W multiscalar films developed a columnar microstructure with single-crystal columns extending the entire $51 \mu \mathrm{m}$ thickness of the film (see Fig. 3). This is not surprising considering that thin Mo films sputtered onto oxidized Si also form a columnar film morphology. ${ }^{19,20}$ The Mo grain size has been shown to increase with thickness at the earliest stages of growth (between 33 and $200 \AA$ ) before developing into columnar grains at thicknesses of approximately $200 \AA .^{20}$ Close inspection of the multiscalar

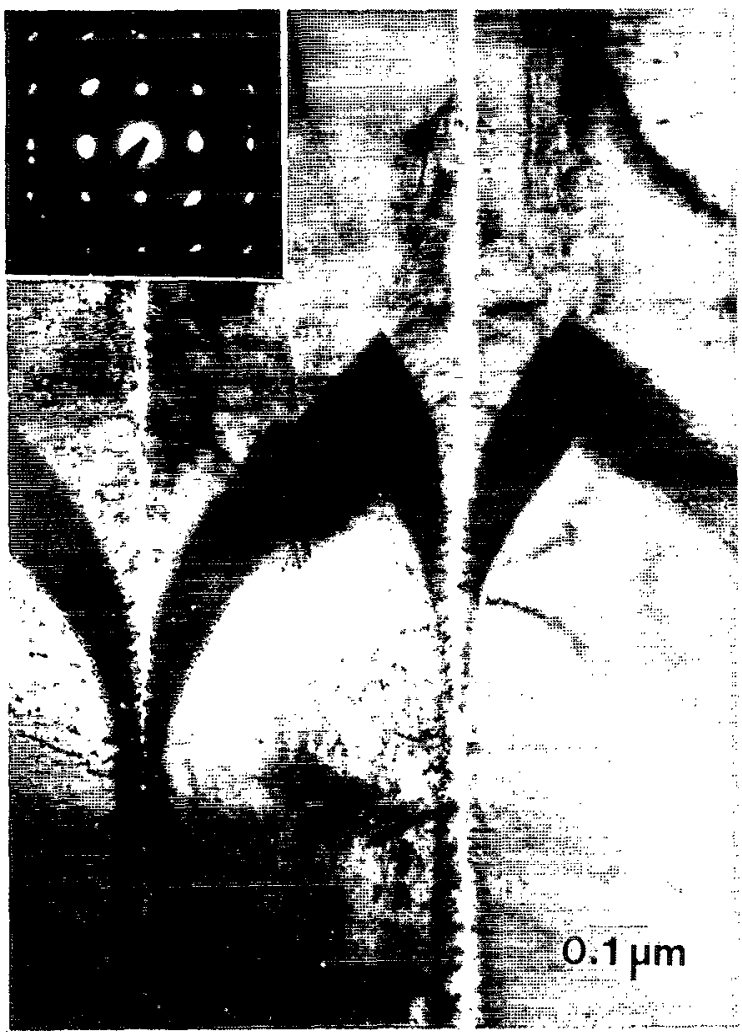

FIG. 3. Cross-sectional TEM bright-field image and corresponding electron-diffraction pattern taken by placing a selected-area aperture around a portion of five columnar grains. Facetted growth front is marked by the Mo/W strengthening phase.

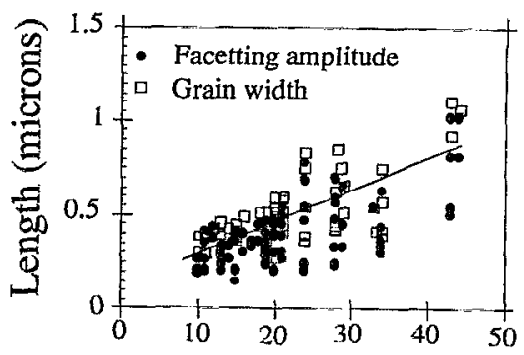

Film thickness (microns)

FIG. 4. Grain width ( $\square$ ) and amplitude of facetting (9) of a typical $51-\mu \mathrm{m}$-thick multiscalar film as a function of film thickness.

films using TEM confirmed that the width of the long columns scaled with film thickness (see Fig. 4). As shown in Fig. 2, the columnar width in the plane of the wafer surface increased from submicrometer-size nuclei at the early stages of growth to larger $(>1 \mu \mathrm{m}$ width) crystallites at film thicknesses of $50 \mu \mathrm{m}$. In plan view, the column width at the film surface was not equiaxed. Columns in both sets of multiscalar films exhibited an aspect ratio ranging from 1:2 to $1: 4$ oriented with a common in-plane texture (see Fig. 5).

Evidence of strong texture throughout the multiscalar film is shown in a diffraction pattern taken by placing a selected-area aperture around a portion of $\sim 5$ columnar structures (inset in Fig. 3). Using diffraction information, transmission electron microscopy has revealed that the columns grew in a $\langle 110\rangle$ body-centered-cubic direction with a weaker $\langle 110\rangle$ in-plane texture. This texture within $\mathrm{Mo} / \mathrm{W}$ multilayer films has been confirmed and analyzed in greater detail using two x-ray techniques-pole figure and white-beam topographical analyses using a synchrotron source. Both confirmed that these films were highly textured and that the preferred direction of growth was indeed $\langle 110\rangle .^{21} \mathrm{X}$-ray techniques have also indicated that the textured columnar structures grew approximately $4^{\circ}$ from the $\mathrm{Si}\langle 100\rangle$ substrate normal. Misoriented (with respect to the substrate normal) growth morphologies have been

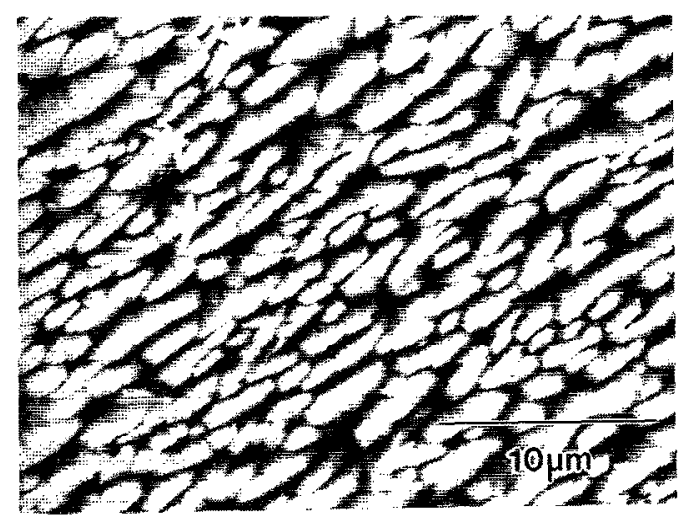

FIG. 5. Plan-view SEM micrograph of facetted multiscalar film surface. 


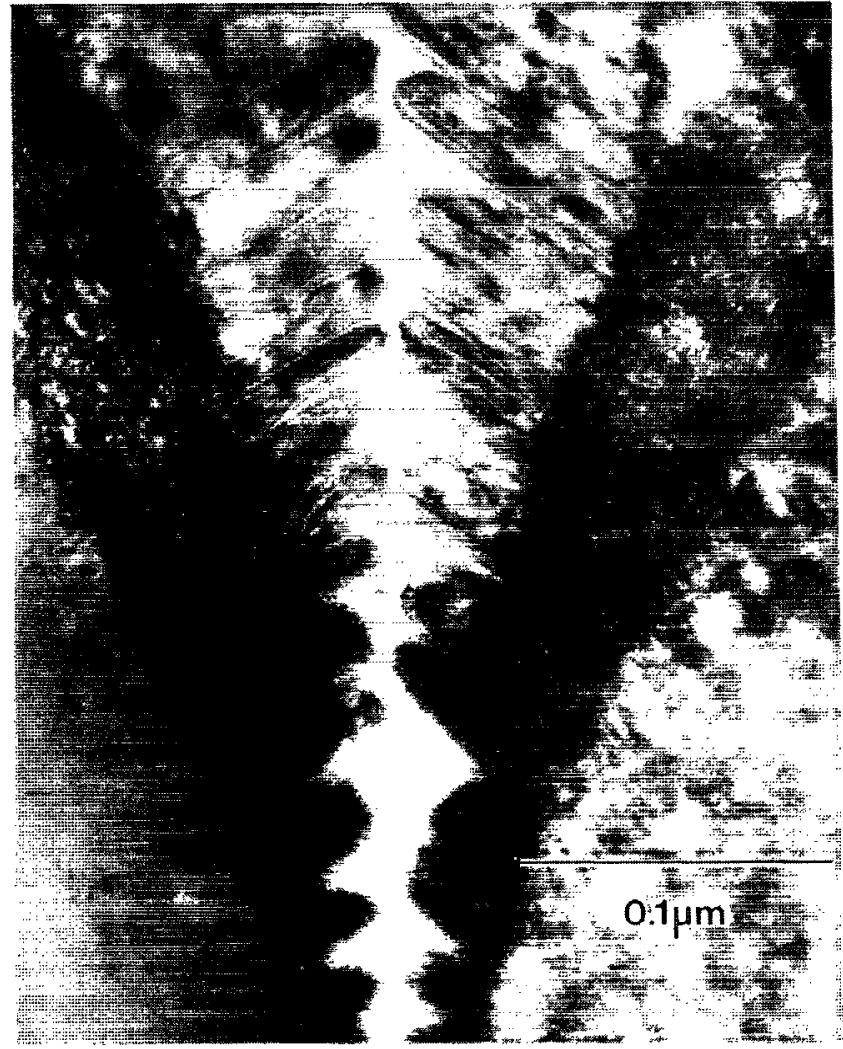

FIG. 6. Enlarged view of microvoids at a grain boundary.

shown to exist in a number of thin-film systems; column orientation typically depends on the substrate/source geometry and follows the tangent rule. 22,23

Transmission electron microscopy has shown that a complex growth front (using the fine-scale $\mathrm{Mo} / \mathrm{W}$ strengthening phases as marker layers) developed within the columns at an early stage of film deposition and continued to form with increasing thickness. As shown in Fig. 3 , near the center of the column, the growth front has facetted primarily along the $\{100\}$ planes of the film. Closer to the grain boundary, however, the growth front deviated from forming exclusively along $\{100\}$ bodycentered-cubic planes. The amplitude of facetting, marked by the strengthening phases in the film, developed within each column was measured to increase with film thickness (see Fig. 4). Microvoids formed during growth at the column boundaries within the film. Trapezoidal voids were measured to be on the order of $150-500 \AA$ in diameter and located along the boundary (see Fig. 6).

The high-resolution transmission electron microscopy (HRTEM) image in Fig. 7 shows several $\sim 40 \AA$-thick Mo and $\mathrm{W}$ layers within one particular strengthening phase. Continuous lattice fringes extend through all layers and phases. These data suggest that a high degree of coherence is present within the multilayer stack.

\section{B. Mechanical properties}

Vickers hardness of both sets of $\mathrm{Mo} / \mathrm{W}$ multiscalar sheets $(1 \mu \mathrm{m}$ toughening phase and $5 \mu \mathrm{m}$ toughening

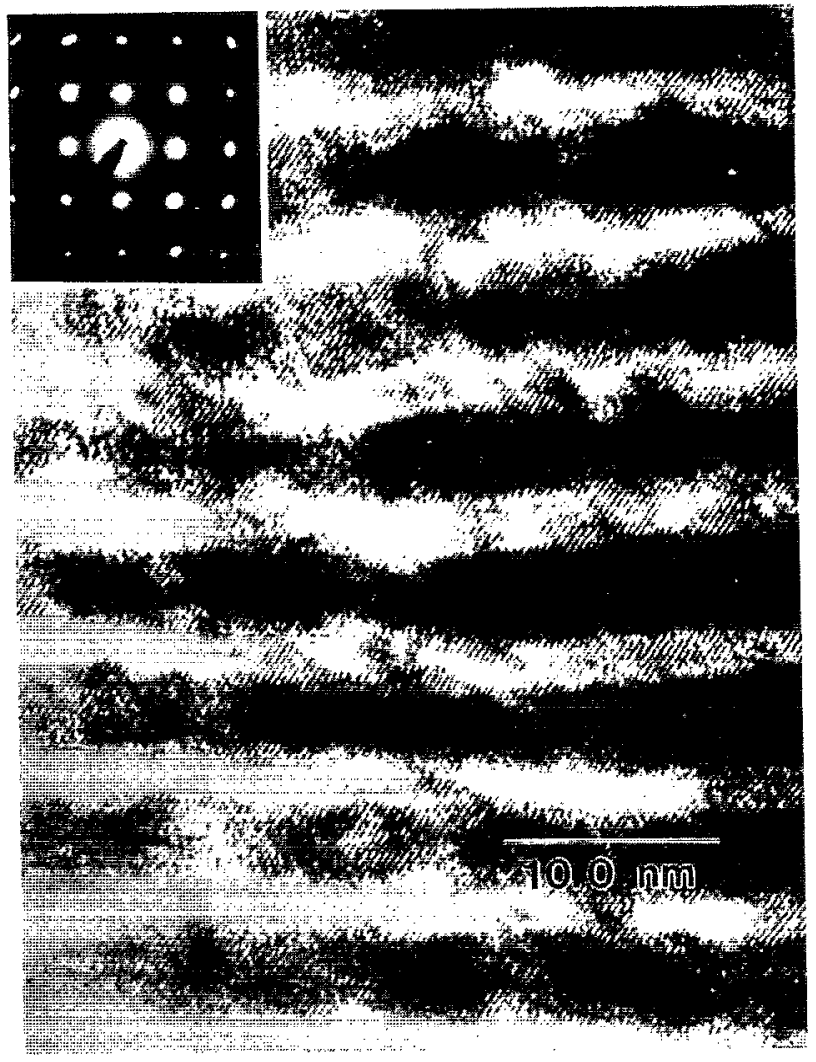

FIG. 7. Cross-sectional high-resolution TEM micrograph of several $\sim 40$ $\AA$ Mo and $\mathrm{W}$ layers comprising a multiscalar strengthening phase. Inset shows corresponding electron-diffraction pattern.

phase) along with reference bulk hardness values for pure Mo and pure $W$ are shown as a function of load in Fig. 8. The hardness of $\mathrm{Mo} / \mathrm{W}$ multiscalar films increased with depth of penetration at low loads and attained a constant value after penetration of a significant portion of the film. The $51-\mu \mathrm{m}$-thick films grown with a $1 \mu \mathrm{m}$ Mo toughening phase attained a hardness of $H_{v}=430 \pm 30 \mathrm{~kg} / \mathrm{mm}^{2}$ after

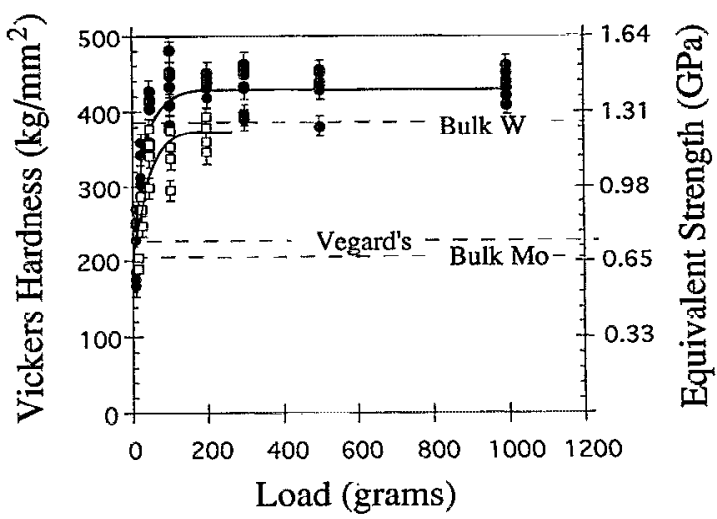

FIG. 8. Vickers hardness $H_{v}$ as a function of load for both $51-\mu \mathrm{m}$-thick $\mathrm{Mo} / \mathrm{W}$ multiscalar films containing $1-\mu \mathrm{m}$-thick toughening layers ( and $31-\mu \mathrm{m}$-thick Mo/W multiscalar films containing $5-\mu \mathrm{m}$-thick toughening components $(\square)$. Also shown are bulk Mo and bulk W hardness values. 
penetration of $12 \%$ of the film thickness. This value remained constant up to loads of $1000 \mathrm{~g}$ (depths of penetration $\sim 23 \%$ of the sheet thickness). The $31-\mu \mathrm{m}$-thick Mo/W multiscalar films, grown with a 5- $\mu$ m-thick toughening layer, attained a hardness value of $\sim 375 \pm 30 \mathrm{~kg} /$ $\mathrm{mm}^{2}$. Within the experimental error, the hardness of the set with a $5 \mathrm{~mm}$ toughening layer is slightly less than that of the $1 \mu \mathrm{m}$ layer. Both types of multiscalar films exhibited more than a $100 \%$ increase in hardness over that predicted by a simple rule of mixtures (based on atomic percent of elemental Mo and elemental $\mathrm{W}$ ) for bulk values. ${ }^{24}$ The enhanced strength of both sheets was on the order of the strength of bulk W (the harder of the two component materials). Yield stresses (shown on the right-hand-side scale of Fig. 8) converted from hardness using the relation $H_{v} \sim 3 \sigma_{y}$, display the strength of these materials was on the order of 1.2-1.4 GPa. All of the indentations in these $\mathrm{Mo} / \mathrm{W}$ multilayer sheets were symmetric about the center of the indent, regardless of orientation within the plane of the film, and exhibited no cracking.

Uniaxial tensile testing has also shown evidence for strength accompanied by toughness in Mo/W multiscalar films. Both sets (5- and $1-\mu \mathrm{m}$-thick toughening layers) of multiscalar films were pulled to a maximum stress of $\sim 260$ $\mathrm{MPa}$ before "unzipping" across the width of the specimen. ${ }^{18}$ After initial failure, the samples with a $5 \mu \mathrm{m}$ toughening layer continued to be strained up to $\sim 1.2 \%-2.4 \%$ engineering strain, while the films with a $1 \mu \mathrm{m}$ toughening layer failed without evidence of ductility.

\section{DISCUSSION}

Columnar morphologies have been observed in thinfilm systems for a number of years. ${ }^{25-29}$ The microstructure of metallic thin films has been explained using zone models. Movchan and Demchishin ${ }^{30}$ proposed a zone model which was modified by Thornton ${ }^{31}$ and more recently by Grovenor, Hentzell, and Smith. ${ }^{32}$ These works have shown that polycrystalline thin-film microstructures can be classified into either three or four characteristic zones and that zone structures depend on substrate temperature, sputtering gas pressures, deposition rate, and other variables. Grovenor and co-workers suggest that the microstructure developed in zone I (substrate temperatures typically below $\sim 0.3 T_{m}$, where $T_{m}$ is the melting temperature of the condensate) is a result of continued grain renucleation during deposition. It has been stated that zone-II (substrate temperatures between $0.3 T_{m}$ and $0.5 T_{m}$ ) microstructures are dominated by surface diffusion and grain-boundary mobility. Zone-II microstructures start with equiaxed grains before coalescing into single-crystal, heavily facetted structures. Thornton and Grovenor and co-workers have each characterized the zone $(T)$ as a transition zone between zone I and zone II. Zone- $T$ structures develop from the combination of mechanisms specific to zone-I and II structures.

The multiscalar films in the present study exhibit features characteristic of zone-II structures despite the low growth temperatures $\left(T<300^{\circ} \mathrm{C}, T / T_{m}<0.19\right)$. This is in contrast to an earlier study which determined the zone-II transformation temperature for Mo condensates to be roughly $700{ }^{\circ} \mathrm{C}\left(T / T_{m}=0.34\right) .{ }^{33}$ As discussed in Sec. IV, multiscalar films contained strongly textured $(\langle 110\rangle)$ columnar structures. TEM has shown that these columnar structures consist of large, single-crystal columns, except at the initial stages $(<1 \mu \mathrm{m})$ of growth. The facetted growth fronts suggest that surface diffusion plays a large role in the development of multiscalar film microstructure. Facetting began to occur within the single-crystal columns at an early stage of growth and continued to develop as the width of the columnar grains increased. The amplitude of facetting (as marked by the strengthening phases) was shown in Fig. 4 to increase with film thickness. The presence of facetting of the growth front and evolution of an amplitude scaling with film thickness is further evidence of a zone-II morphology.

Vickers indentation measurements suggest that the hardness of multiscalar films is due to the strengthening phase, not the toughening phase. This conclusion is drawn because increasing the thickness of the toughening phase alone does not significantly alter the hardness. Each of the two sets of multiscalar films exhibited high strengths on the order of $1.2-1.4 \mathrm{GPa}\left(H_{v} \sim 375-430 \mathrm{~kg} / \mathrm{mm}^{2}\right)$, exceeding that predicted by a simple rule of mixtures. In addition, the second set of samples (with a $5 \mu \mathrm{m}$ toughening component) was $\sim 1 / 2$ the total thickness of the first set, hence $\sim 1 / 2$ the grain width. If a Hall-Petch mechanism was present, then the strength should increase with decreasing grain size in contrast to the data. The slight decrease in the hardness of films with a thicker toughening phase can be explained by the difference in the number of strengthening phases per unit thickness. For a given depth of indentation, the tip penetrates up to five times more $\mathrm{Mo} / \mathrm{W}$ multilayers in films grown with a $1 \mu \mathrm{m}$ toughening phase compared to films with a 5- $\mu$ m-thick Mo layer.

The growth of thin layers of Mo and W in the multiscalar strengthening phases provides the structural prerequisites necessary for activation of several different strengthening mechanisms. Increases in strength could arise from a mechanism similar to that described by Orowan for the movement of dislocations through a crystal containing precipitate particles. The radius of a bowed dislocation, pinned by each multilayer interface, will scale inversely with layer thickness. In a multilayer stack, smaller layer thicknesses increase the resistance to dislocation motion. For decreasing layer thicknesses, additional force is required to propagate a dislocation, with increases in yield stress being $\sim 1 / d$, where $d$ is the layer spacing. Multiscalar films could also be strengthened by the mechanism proposed by Koehler for multilayer composites. Within each single-crystal column, the strengthening phases consist of $\sim 40$-Ä-thick, epitaxial, alternated high/low elastic moduli materials (Young's modulus ratio: $E_{\mathrm{W}} / E_{\mathrm{Mo}}=1.27$ ). According to Koehler, multilayer composites of alternated epitaxial, thin layers of high/low elastic moduli materials can render a Frank-Read source inoperative and produce virtually infinite image forces on dislocations in all layers. The strength of these multilayers should then approach the value of the theoretical yield strength of the soft layer. 
Determination of the exact strengthening mechanism(s) present in multiscalar films is difficult. The well-ordered stack of $\mathrm{Mo} / \mathrm{W}$ multilayers is complicated by the additional role that the microstructure (i.e., voids, facetting, etc.) may play.

A complete understanding of the mechanical properties of multiscalar films must include the role of microvoids. The existence of voids at the column boundaries appears to be influenced by the competitive growth between surface facets in neighboring columns. The trapezoidal shape of the voids (shown in Fig. 6) supports this argument, but the exact mechanism by which microvoids form is likely a more complicated process involving surface energetics, surface diffusion, and perhaps shadowing. The microvoids are present along the entire length of the columnar boundaries, but do not continue to form after two neighboring columns coalesce. Multiscalar films in this study have a much more dense ( $<5 \%$ void density) structure than typical zone-I and zone- $T$ structures. ${ }^{31}$ Voids could be influencing the mechanical properties of multiscalar films by altering the roles of stress, grain-boundary mobility, and grain-boundary diffusion in the development of microstructure.

Several factors must be investigated to determine the origin of Mo/W zone-II microstructures at low growth temperatures. As suggested elsewhere, the effects of residual strcss could act as a driving force for grain-boundary migration and change the temperature ranges which distinguish the different zones of columnar microstructure. ${ }^{31}$ Previous work on sputtered Mo and $\mathrm{W}$ has shown that large residual stresses develop in thin (25-800 $\AA$ ) films and that the residual stress locked into Mo and $W$ films depends on layer thickness. Large stresses, therefore, could be present in the multilayer stack comprising the strengthening phases and affect the development of film microstructurc. In addition, many growth parameters during sputtering can influence the development of multiscalar film microstructure. Fabrication of the films in this study included multiple deposition rates and sample rotation (i.e., multiple angles of incidence) which can further complicate the development and interpretation of film structure. $^{34}$

Mechanical tests suggest that zone-II microstructures are suitable for controlling the film structure at each scale, in order to tailor the mechanical properties for specific applications. A multiscalar approach offers the ability to tailor both the toughness and strength of thin films by changing the relative amounts (volume percent) of the two phases. Tensile tests have shown that Mo/W multiscalar films, containing a larger fraction of the toughening component (Mo), exhibit more toughness. Multiscalar films consisting of a $5-\mu \mathrm{m}$-thick toughening layer continued to be strained up to $\sim 2.4 \%$ strain, while the films consisting of a $1-\mu \mathrm{m}$-thick toughening layer exhibited no evidence of ductility.

\section{SUMMARY}

Mo/W multiscalar films that combine both strength and toughness into a multilayer structure have been fabri- cated. Multiscalar films incorporate several scales of composition modulation into a relatively thick film consisting of two phases-a toughening phase and a strengthening phase. The strengthening phases, in this article, consisted of a stack of thin $(\sim 40 \AA)$ Mo and W layers, while the toughening phases were thick ( 1 or $5 \mu \mathrm{m}$ ) layers of Mo. The microstructure of $\mathrm{Mo} / \mathrm{W}$ multiscalar films was a zone-II microstructure, despite the fact that the growth temperatures $\left(T / T_{m}<0.19\right)$ were below the predicted lower limit $\left(0.3 T / T_{m}\right)$ for zone II. Multiscalar films had a columnar microstructure with single-crystal (textured in the $\langle 110\rangle$ direction) columns extending the entire thickness of the film. In addition, a heavily facetted growth front (as marked by the strengthening phases) formed at the initial stages of growth and continued to develop with increasing film thickness. This evidence showed that surface diffusion influences the development of the multiscalar film microstructure at temperatures $<300^{\circ} \mathrm{C}$. Additional mechanisms including grain-boundary mobility and residual stress could also play a role in the development of this zone-II microstructure. Multiscalar films attained Vickers hardness values of $\sim 400 \pm 30 \mathrm{~kg} / \mathrm{mm}^{2}$, exceeding that predicted by Vegard's law by $\sim 100 \%$, based on bulk hardness values of Mo and W. Hardness data showed that increases in strength were not due to a Hall-Petch mechanism, but were a result of the multilayer strengthening phases. The microstructure and geometry of the Mo/W multilayer suggest that the increased strength could occur via an Orowan or a Koehler mechanism. Mechanical tests have shown that a zone-II microstructure is ideal for controlling the film structure at each scale, in order to tailor the mechanical properties for specific applications.

\section{ACKNOWLEDGMENTS}

The authors are grateful to John Mansfield at the University of Michigan Electron Microbeam Analysis Laboratory (EMAL), Jim Kulman at the University of Michigan Solid State Electronics Laboratory, David Srolovitz, Oleh Karpenko, and Sandra Guy. This work was supported by the U.S. Army Research Office and DARPA under Contract No. DAAL03-91-G-0235.

${ }^{1}$ P. Dhez, Physics, Fabrication and Applicattons of Multilayered Structures (Plenum, New York, 1988).

${ }^{2}$ B. J. Thaler, J. B. Ketterson, and J. E. Hilliard, Phys. Rev. Lett. 41, 336 (1978).

${ }^{3}$ C. Sarrazin, J. P. Riviere, and R. J. Gaboriaud, Phys. Status Solidi A 107, 867 (1988).

${ }^{4}$ W. Blum, Trans. Am. Electrochem. Soc. 40, 307 (1921).

${ }^{5}$ D. S. Lashmore and M. P. Dariel, J. Electrochem. Soc. 135, 1218 (1988).

${ }^{6}$ J. S. Koehler, Phys. Rev. B 2, 547 (1970).

${ }^{7}$ S. L. Lehoczky, J. Appl. Phys. 49, 11, 5479 (1978).

${ }^{8}$ J. W. Cahn, Acta. Metall. 11, 1274 (1963).

${ }^{9}$ S. M. Durbin, J. E. Cunningham, M. E. Mochel, and C. P. Flynn, J. Phys. F 11, L223 (1981).

${ }^{10}$ S. L. Lehoczky, J. Appl. Phys. 41, 1814 (1978).

${ }^{11}$ B. M. Clemens and G. L. Eesley, Phys Rev. Lett. 61, 2356 (1988),

${ }^{12}$ P. Anderson, L.-H. Lin, and R. Thomson, Scrip. Met. Mater. 27, 687 (1992).

${ }^{13}$ M. R. Hilton, R. Bauer, S. V. Didziulis, M. T. Dugger, J. M. Keem, and J. Scholhamer, Surf. Coat. Tech. 53, 13 (1992).

${ }^{14} \mathrm{~J}$. E. Cunningham and C. P. Flynn, J. Phys. F 15, L221 (1985). 
${ }^{15}$ M. Shinn, L. Hultman, and S. A. Barnett, J. Mater. Res. 7, 901 (1992).

${ }^{16}$ R. W. Springer and D. S. Catlett, Thin Solid Films 54, 197 (1978).

${ }^{17} \mathrm{~J}$. Tao, D. Adams, S. M. Yalisove, and J. C. Bilello, Mater. Res. Soc. Symp. Proc. 239, 57 (1992).

${ }^{18}$ M. Vill, S. Guy, D. P. Adams, S. M. Yalisove, and J. C. Bilello (unpublished).

${ }^{19}$ T. J. Vink, M. A. J. Somers, J. L. C. Daams, and A. G. Dirks, J. Appl. Phys. 70, 4301 (1991).

${ }^{20}$ J. Tao, D. P. Adams, S. M. Yalisove, and J. C. Bilello (unpublished).

${ }^{21}$ J. Tao, D. P. Adams, M. Vill, S. M. Talisove, and J. C. Bilello (unpublished).

${ }^{22}$ J. M. Nieuwenhuizen and H. B. Haanstra, Philips Tech. Rev. 27, 87 (1966).

${ }^{23}$ N. G. Nakhodkin, A. I. Shaldervan, A. F. Bardamid, and S. P. Chenakin, Thin Solid Films 34, 21 (1976).

${ }^{24}$ Metals Handbook, Properties and Selection of Metals (American Society of Metals, Metals Park, OH, 1961), Vol. I.
${ }^{25}$ T. M. Donovan and K. Heinemann, Phys. Rev. Lett. 27, 1794 (1971).

${ }^{26}$ D. O. Smith, M. S. Cohen, and G. P. Weiss, J. Appl. Phys. 31, 1755 (1960).

${ }^{27}$ D. K. Pandya, S. K. Barthwal, and K. L. Chopra, Phys. Status Solidi A 32, 489 (1975)

${ }^{28}$ T. Hashimoto, K. Hara, K. Okamoto, and H. Fujiwara, J. Phys. Soc. Jpn. 41, 1433 (1976).

${ }^{29}$ A. G. Dirks and H. G. Leamy, Thin Solid Films 47, 219 (1977).

${ }^{30}$ B. A. Movchan and A. V. Demchishin, Phys. Met. Metallogr. (USSR) 28, 83 (1969).

${ }^{31}$ J. A. Thornton, Ann. Rev. Mater. Sci. 7, 239 (1977).

${ }^{32}$ C. R. M. Grovenor, H. T. G. Hentzell, and D. A. Smith, Acta. Metall. 32, 773 (1984).

${ }^{33}$ R. F. Bunshah, J. Vac. Sci. Technol. 11, 633 (1974).

${ }^{34}$ D. W. Hoffman and J. A. Thornton, J. Vac. Sci. Technol. 16, 134 (1979). 